\title{
The content of carbohydrates in larval stages of Anisakis simplex (Nematoda, Anisakidae)
}

\author{
E. ŁOPIEŃSKA-BIERNAT ${ }^{1}$, K. ŻÓŁTOWSKA ${ }^{1}$, J. ROKICKI ${ }^{2}$ \\ ${ }^{1}$ Department of Biochemistry, Faculty of Biology, University of Warmia and Mazury, Oczpowskiego 1A, 10-957 \\ Olsztyn, Poland; E-mail: ela.lopienska@uwm.edu.pl; ${ }^{2}$ Invertebrate Zoology Division, University of Gdańsk, al. \\ Piłsudskiego 46, 81-378 Gdynia
}

\begin{abstract}
Summary
The content of carbohydrates in $\mathrm{L}_{3}$ and $\mathrm{L}_{4}$ larvae of Anisakis simplex (defined by Rokicki J.) was studied. Glycogen and trehalose were their major reserve sugars. The concentration of saccharides in $\mathrm{L}_{4}$ larvae was 2 - 3-times higher than in $\mathrm{L}_{3}$ larvae. The content of glycogen was 3.68 $\pm 1.24 \mathrm{mg} / \mathrm{g}$ tissue in $\mathrm{L}_{3}$ larvae and $11.68 \pm 1.21 \mathrm{mg} / \mathrm{g}$ tissue in $\mathrm{L}_{4}$ larvae. Trehalose represented $16.17 \%$ of soluble sugars in $\mathrm{L}_{3}$ larvae and $43.04 \%$ in $\mathrm{L}_{4}$ larvae. The contents of maltose, higher polymers of glucose (1.5-times) and myoinositol (1.2-times) in $\mathrm{L}_{4}$ were higher than in $\mathrm{L}_{3}$ larvae. After starving the $\mathrm{L}_{3}$ larvae of the parasite for $48 \mathrm{~h}$ at $4^{\circ} \mathrm{C}$, the contents of trehalose increased 5-fold and that of glycogen by $20 \%$, while at $37^{\circ} \mathrm{C}$ the contents of glycogen was ca. $30 \%$ higher and that of trehalose $40 \%$ less than in larvae freshly isolated from the host $(\mathrm{p}<0.01)$. The data obtained during starving the $\mathrm{L}_{3}$ larvae of $A$. simplex may be a consequence the role of trehalose as protective compound at stress condition. We suggest that probably in higher temperatures it acts as first a source of energy, and it also might serve to restore the levels of glycogen.
\end{abstract}

Key words: Anisakis simplex; trehalose; glycogen; carbohydrates

\section{Introduction}

Anisakis simplex is a parasite of the alimentary system of marine mammals. The nematode may become the cause of pathologic changes in the stomach and intestines of people. The infestation of humans, as an opportunity host, occurs as a consequence of consumption of raw or insufficiently frozen fish (Williams \& Jones, 1976; Adams et al., 1997). Glycogen and trehalose are important sources of energy for parasitic nematodes (Von Brand, 1979). The concentration of glycogen varies in individual species of nematodes and also changes within one species depending on the stage of development. The content of glycogen is much higher in organisms living in oxygen-poor environments. A. simplex also belongs to that group. It is known that glycogen is metabolized quickly when the host is starved, for that reason large reserves of glycogen are accumulated by stomachintestinal nematodes (Von Brand, 1979). In Ascaris lumbricoides the level of that polysaccharide ranges from 14 to $24 \%$, while in the muscles it may represent even $70 \%$ of their dry matter. Also the intestines, hypoderm and reproductive system of that nematode are rich in glycogen (Lee \& Atkinson, 1976). Presence of glycogen grains was also observed in the epithelium cells of the intestine in $\mathrm{L}_{3}$ larvae of A. simplex (Smith \& Wootten, 1978). Trehalose is of special importance for parasites owing to its physical and chemical properties. Besides the function of energy reserve, it fulfills a protective role. Free-living and parasitic nematodes synthesize trehalose in reaction to desiccation and cooling (Womersley \& Smith, 1981; Wharton, 1994; Womersley \& Higa, 1998; Wharton et al., 2000). In parasites of animals trehalose is the reserve sugar and a transport form supplying glucose to tissues. Behm (1997) considers trehalose to be the main sugar circulating in the bodies of nematodes.

Fragmentary studies on metabolism of carbohydrates in $\mathrm{L}_{3}$ larvae of A. simplex, were carried out during 1960's. They identified the existence of the glycolytic path and that the larvae of nematodes do not use external sources of glucose (Smith \& Wootten, 1978). Both those observations suggest that the invasive stages of the parasite use the earlier accumulated reserves of saccharides. Although almost 30 years have passed, the basic data on the type and level of the reserves sugars in A. simplex still missing. Investigating those issues was the goal of this study. 


\section{Materials and Methods}

\section{Materials}

The material for the study consisted of $\mathrm{L}_{3}$ and $\mathrm{L}_{4}$ larvae of $A$. simplex s. s. identified by Rokicki J. The $\mathrm{L}_{3}$ larvae of $A$. simplex were isolated from fresh Baltic herring (Clupea harengus). They also formed the starting material for in vitro culture for obtaining $\mathrm{L}_{4}$ stage of that nematode in 9 th day. The in vitro culture was prepared according to the modified Grabda (1976) method at $37^{\circ} \mathrm{C}$ in the atmosphere with $5 \% \mathrm{CO}_{2}$ in the WTB Binder incubator type CB 150 (Łopieńska et al., 2001).

Starving the $\mathrm{L}_{3}$ larvae of $A$. simplex at $4^{\circ} \mathrm{C}$ and $37^{\circ} \mathrm{C}$ was achieved by holding the nematodes freshly isolated from the herrings for 6 days without any nutrients in $0.65 \%$ $\mathrm{NaCl}$ at two temperatures: $4^{\circ} \mathrm{C}$ and $37^{\circ} \mathrm{C}$.

\section{Preparation of extracts for quantitative determination of} saccharides

$\mathrm{L}_{3}$ or $\mathrm{L}_{4}$ larvae, after flushing a number of times in $0.65 \%$ $\mathrm{NaCl}$, were dried on filtration paper and weighted. They were homogenized in a manual, glass homogenizer with distilled water at $1 / 10 \mathrm{w} / \mathrm{v}$. The homogenates were placed in boiling water bath for $5 \mathrm{~min}$ to remove proteins and inactivate the enzymes, cooled and centrifuged at $800 \times \mathrm{g}$ for $15 \mathrm{~min}$ at $4^{\circ} \mathrm{C}$. The supernatant served marking the contents of carbohydrates.

\section{Analysis of carbohydrates}

Glucose was marked using glucose oxidase by applying the kit by Cormay (Lublin, Poland). Glycogen was measured by Sölling and Esmann (1975) micro-method. The contents of maltose and maltotriose were determined quantitatively after separation of sugars present in the extracts using chromatography on Whatman's 3 paper in the developing system of solvents: n-butanol/glacial acetic acid/ water at $12 / 3 / 5$. On the basis of the standard spot the position of the study sugar in larvae extracts was determined. Maltose and maltotriose were eluted from the paper in $1 \mathrm{ml}$ of distilled water at $100^{\circ} \mathrm{C}$. The contents of reducing sugars in the eluate were determined by applying the ParkJohnson method (after Lisowska, 1970). The content of trehalose was determined using the enzymatic method (Kienle et al., 1993). The separation of soluble carbohy- drates was done on the SPB-1 column in a GC-14A Shimadzu GLC chromatograph equipped with a flame-ionizing detector.

The content of studied sugars was expressed in mg per $\mathrm{g}$ of tissue. The results represent the average values of nine repetitions of the experiments. The results obtained were analyzed by Student's t test.

\section{Results}

The concentrations of the studied sugars, except maltotriose, were several times higher in $\mathrm{L}_{4}$ larvae (from culture, 4 days after moulting) of $A$. simplex than in $\mathrm{L}_{3}$ larvae from fish (Table 1). The differences in the levels of sugars' contents between those stages were statistically significant in all cases. In both larval stages, the contents of glycogen and trehalose were the highest. The contents of glycogen and glucose in $\mathrm{L}_{4}$ larvae were 3-times and trehalose as much as over 4-times higher than in $\mathrm{L}_{3}$ larvae (Table 1). On the other hand, the percentage share of individual carbohydrates in the total pool of sugars in larvae of both stages was similar (Table 1). Glycogen represented over 62 $\%$, and glucose ca. $6.4-7 \%$ of the total sugars. The share of trehalose was slightly higher in $\mathrm{L}_{4}$ larvae than in $\mathrm{L}_{3}$ larvae. The contents of maltose and maltotriose were 1.5times higher in $\mathrm{L}_{4}$ larvae than in $\mathrm{L}_{3}$ larvae (Table 1). Analysis of soluble sugars by means of gas chromatography showed that trehalose was one of the major sugars in that

Table 1. The content of carbohydrates in the larvae $\mathrm{L}_{3}$ and $\mathrm{L}_{4}$ of Anisakis simplex ${ }^{1}$

\begin{tabular}{lccccc}
\hline \multirow{2}{*}{ Sugar } & \multicolumn{5}{c}{ Stage } \\
\cline { 2 - 3 } \cline { 2 - 3 } \cline { 5 - 6 } & \multicolumn{2}{c}{$\mathrm{L}_{3}$} & \multicolumn{2}{c}{$\mathrm{L}_{4}$} \\
\cline { 2 - 3 } & $\mathrm{mg} / \mathrm{g}_{\text {tissue }}{ }^{\mathrm{a}}$ & $\%^{\mathrm{b}}$ & & $\mathrm{mg} / \mathrm{g}_{\text {tissue }}{ }^{\mathrm{a}}$ & $\%^{\mathrm{b}}$ \\
\hline Glycogen & $3.68 \pm 1.24^{*}$ & 63.67 & & $11.68 \pm 1.21$ & 62.06 \\
Glucose & $0.40 \pm 0.18^{*}$ & 6.92 & & $1.21 \pm 0.22$ & 6.42 \\
Maltose & $0.19 \pm 0.02^{*}$ & 3.29 & & $0.32 \pm 0.09$ & 1.75 \\
Maltotriose & $0.34 \pm 0.07^{*}$ & 5.88 & & $0.47 \pm 0.6$ & 2.55 \\
Trehalose & $1.17 \pm 0.56^{*}$ & 20.24 & & $5.14 \pm 0.79$ & 27.31 \\
\hline
\end{tabular}

${ }^{*} \mathrm{p}<0.01 ;{ }^{\mathrm{a}}$ mean $\pm \mathrm{SD} ; \mathrm{n}=9 ;{ }^{\mathrm{b}}$ the percentage by total sugars

Table 2. The content of soluble carbohydrates and myoinositol in the larvae of Anisakis simplex ${ }^{1}$

\begin{tabular}{lccccc}
\hline Sugar & \multicolumn{3}{c}{ Stage } \\
\cline { 2 - 3 } \cline { 5 - 6 } & \multicolumn{2}{c}{$\mathrm{mg} / \mathrm{g}_{\text {tissue }}{ }^{\mathrm{a}}$} & & \multicolumn{2}{c}{$\mathrm{L}_{4}$} \\
\cline { 2 - 3 } \cline { 5 - 6 } Glucose $\alpha$ & $0.314 \pm 0.028^{* *}$ & 6.40 & & $0.510 \pm 0.070$ & 3.94 \\
Glucose $\beta$ & $0.313 \pm 0.057^{* *}$ & 6.38 & & $0.700 \pm 0.162$ & 5.41 \\
Maltose & $0.260 \pm 0.035^{* *}$ & 5.30 & & $0.450 \pm 0.050$ & 3.48 \\
Trehalose & $0.793 \pm 0.370^{* *}$ & 16.17 & & $5.565 \pm 0.231$ & 43.04 \\
Higher polymers of glucose & $3.150 \pm 0.960^{* *}$ & 64.25 & & $5.620 \pm 0.860$ & 43.47 \\
Myoinositol & $0.073 \pm 0.005^{*}$ & 1.49 & & $0.085 \pm 0.005$ & 0.66 \\
\hline
\end{tabular}

$* * \mathrm{p}<0.01 ; * \mathrm{p}<0.05 ;{ }^{\mathrm{a}}$ mean $\pm \mathrm{SD} ; \mathrm{n}=9{ }^{\mathrm{b}}{ }^{\mathrm{b}}$ the percentage by total soluble sugars 


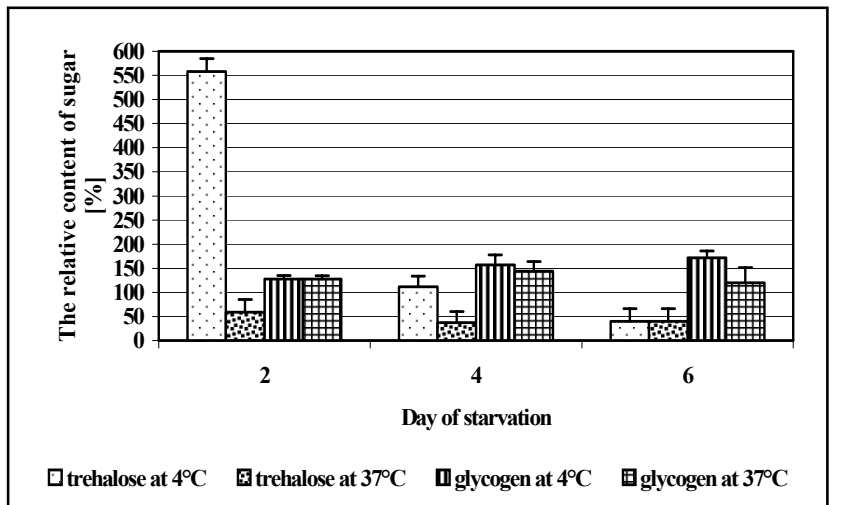

Fig. 1. The content of trehalose and glycogen in level of sugars in freshly isolated larvae of Anisakis simplex

(As $100 \%$ of trehalose was $3.35 \mathrm{mg} / \mathrm{g}_{\text {tissue }}$, glycogen $19.85 \mathrm{mg} / \mathrm{g}_{\text {tissue }}$ )

group of carbohydrates (Table 2). Trehalose represented $16.17 \%$ of the total pool of soluble carbohydrates in $\mathrm{L}_{3}$ larvae and $43.04 \%$ of that pool in $\mathrm{L}_{4}$ larvae (Table 2). The trehalose concentration measured by that method was as much as 7-times higher in the older larvae than in the younger ones. The contents of maltose and higher polymers of glucose in $\mathrm{L}_{4}$ larvae were higher by ca. 1.5-times, as well as myoinositol were higher by ca. 1.2-times than in $\mathrm{L}_{3}$ larvae. The level of glucose was also relatively high. In $\mathrm{L}_{4}$ larvae its content was almost 2-times higher than in $\mathrm{L}_{3}$ larvae (Table 2). The discussed differences were statisticcally significant in all cases (Table 2).

To show the rate of utilization, i.e. to show indirectly the participation of the studied sugars in the metabolism of $\mathrm{L}_{3}$ larvae, the experiment of culturing $\mathrm{L}_{3}$ larvae without nutrients at two temperatures, i.e. 4 and $37^{\circ} \mathrm{C}$ was carried out. The results were surprising. During the initial two days of keeping the larvae at $4^{\circ} \mathrm{C}$ the content of trehalose increased over 5 -fold. Also the level of glycogen was higher by ca. $27 \%$ than that measured in the larvae freshly isolated from the fish. During the following days of starvation the content of glycogen was maintained at a similar level and on days 4 and 6 it was higher by ca. $60 \%$ than at the beginning of the experiment (Fig. 1). On the other hand the concentration of trehalose decreased by ca. $60 \%$ during the last two days of the experiment. It should be mentioned that $A$. simplex larvae live at $4^{\circ} \mathrm{C}$ but do not show any mobility. Their survival assessed by whether they moved in response to stimulation with needle.

A different situation was observed at $37^{\circ} \mathrm{C}$. In that temperature the parasite larvae are mobile. That temperature corresponds to the one encountered by $\mathrm{L}_{3}$ larvae after entering the body of the mammal. After two days of starving the larvae at $37^{\circ} \mathrm{C}$ the trehalose concentration decreased by ca. $40 \%$ while the content of glycogen increased by $30 \%$ (Fig. 1). During the following days of starvation the level of trehalose was maintained at a similar level, lower by ca. $60 \%$ than at the beginning of the experiment while the level of glycogen was still higher by ca. $20 \%$ (Fig. 1).

\section{Discussion}

Nematodes accumulate and use mainly glycogen, trehalose and glucose (Von Brand, 1979). In the body of A. simplex larvae, which was also confirmed in this study, besides the three above-mentioned sugars, maltose, maltotriose and myoinositol are also present but in lower quantities (Tables 1 and 2).

Glycogen is the major reserve sugar in both larval forms of A. simplex. Its share in the overall pool of carbohydrates of both $A$. simplex larvae was very similar at $63.67 \%$ in $\mathrm{L}_{3}$ and $62.06 \%$ in $\mathrm{L}_{4}$ larvae (Table 1). The percentage content of glycogen (dry weigh) in the bodies of parasite larvae was not very high as compared with stomach-intestinal parasites of other vertebrates (Von Brand, 1979). It was $0.37 \%$ for $\mathrm{L}_{3}$ larvae and $1.17 \% \mathrm{~L}_{4}$ larvae of $A$. simplex. $\mathrm{A}$ similar level of glycogen was registered for another nematode of Anisakidae family - Hysterothylacium aduncum. The concentration of glycogen in larvae $\mathrm{L}_{3}$ of that fish parasite was 0.29 \% (Źółtowska et al., 2002).

It was observed while comparing the glycogen and glucose contents in larvae and mature H. aduncum and Cystidicola farionis, that the older developmental stages of the marine fish parasite nematodes have the higher sugar reserve (Żółtowska et al., 2001, 2002). Similarly, in this work the level of glycogen was over 3-times higher in older stages of the larvae $\left(\mathrm{L}_{4}\right)$ of $A$. simplex than in $\mathrm{L}_{3}$ larvae. $\mathrm{L}_{4}$ larvae also contained 3-times more glucose and 5-times more trehalose than $\mathrm{L}_{3}$ larvae (Table 1). It was observed that the consumption of glycogen increased in larval forms of A. suum migrating through the body of the host with the decreasing oxygen concentration in the environment (Von Brand, 1979). Maybe accumulation of larger reserves of saccharides by $\mathrm{L}_{4}$ than by $\mathrm{L}_{3}$ larvae of $A$. simplex found in this study was one of the manifestations of similar adaptation of that stage to the relatively anaerobic conditions found in their natural environment, i.e. the alimentary tract of mammals.

The relative proportions of glycogen and trehalose contents in the bodies of individual nematodes differ. Usually, there is more glycogen than trehalose. Such a situation was found in parasitic nematodes: A. suum, Trichinella spiralis, Pseudoterranova decipens, larvae of $C$. farionis, mature $H$. aduncum and free living nematodes Turbatrix aceti, $\mathrm{Pa}$ nagrellus redivivus and Ditylenchus myceliophagus (Von Brand, 1979; Womersley \& Smith, 1981; Womersley et al., 1982; Żółtowska et al., 2001, 2002). Also A. simplex larvae contained more glycogen than trehalose - in $\mathrm{L}_{3}$ larvae - 3-times and in $\mathrm{L}_{4}$ larvae 2-times (Table 1). However, it should be remembered that the level of both those carbohydrates changes and depends on the current physiological condition of the individual. Żóltowska et al. (1998) observed, depending on the composition of the medium and culturing time, differences in contents of glycogen in muscles of A. suum within a wide range of from $0.05 \%$ up to $6.21 \%$.

The nutritional status of $\mathrm{L}_{3}$ larvae of $A$. simplex is not quite 
clear. In case of older $\mathrm{L}_{3}$ larvae, the alimentary system is developed but it does not participate in the intake and digestion of food (Grabda, 1976). Also our observations during in vitro culturing of the larvae of that parasite are in line with the above finding. Presence of nutrients stained with haemoglobin in the alimentary tract was visible only from the late $\mathrm{L}_{4}$ larvae stage. It is assumed that $\mathrm{L}_{3}$ larvae intake simple nutrients through the cuticle because their growth is clearly visible. That is also supported by the results of in vitro culturing where artificial media with strictly defined composition were applied (Iglesias et al., 1997). Also in paratenic hosts the growth of parasite larvae up to as much as $36 \mathrm{~mm}$ occurs (Strømmes \& Andersen, 2003). Poor penetration of glucose through body wall was experimentally confirmed only for some nematodes, including $A$. suum, Angiostrongylus cantonensi and Mermis nigrescens larvae (Von Brand, 1979). No similar experiments have been done for $A$. simplex. The conclusions drawn by Williams and Jones (1976) on the basis of survival of $A$. simplex larvae in sea water with different concentrations of salt indicate that the cuticle of Anisakis is relatively impermeable for non-particulate compounds soluble in water. The authors explain the unusual survival capability of $\mathrm{L}_{3}$ larvae in various external conditions by properties of their cuticle.

The above observation assumes that non-feeding $\mathrm{L}_{3}$ larvae of $A$. simplex must obtain their energy to a large extent from endogenous reserve compounds, including sugars. The investigations of this study on consumption of glycolgen and trehalose during six day culturing of $A$. simplex $\mathrm{L}_{3}$ larvae freshly isolated from fish in $0.65 \% \mathrm{NaCl}$ solution in two temperatures $\left(4^{\circ} \mathrm{C}\right.$ and $\left.37^{\circ} \mathrm{C}\right)$, partly confirmed that suggestion and, what is more, provided indications for further focused studies. An attempt was made to follow the changes in values for major carbohydrates, glycogen and trehalose in thermal conditions similar to those in the body of the paratenic and definitive host of $\mathrm{L}_{3}$ larvae of $A$. simplex. The first of the chosen temperatures, $\left(4^{\circ} \mathrm{C}\right)$, corresponds to the temperature of sea water in which herrings (approximate of temperature, cold-blooded animal) - the paratenic hosts of the parasite stay during the spring season while the temperature of $37^{\circ} \mathrm{C}$ corresponds to the body temperature of maritime mammals - the ultimate hosts. It was expected that changes to the level of sugars at $4^{\circ} \mathrm{C}$ would be less than at $37^{\circ} \mathrm{C}$, because the increase of temperature is clearly related the intensification of basic metabolism. Also, a significantly higher mobility of nematodes at $37^{\circ} \mathrm{C}$ should result in a higher consumption of carbohydrates. In numerous intestinal nematodes an increased consumption of glycogen was observed during periods of starvation. Narain et al. (1995) recorded a day decrease of glycogen level in Ascaridia galli starved at $37^{\circ} \mathrm{C}$ by 11.2 $\%$ during the first day and by ca. $80 \%$ after the following two days. It was calculated that in case of lack of nutrition A. suum consumes $1.3 \mathrm{~g}$ glycogen per $100 \mathrm{~g}$ body weight per 24 hours (Von Brand, 1979). The results obtained in this study after two days culturing of $\mathrm{L}_{3}$ larvae of $A$. simp- lex without nutrients were different. In larvae maintained at $4^{\circ} \mathrm{C}$ an over 5-times increase in the level of trehalose and $20 \%$ of glycogen was observed (Fig. 1). During the same time in larvae cultured at $37^{\circ} \mathrm{C}$ the content of glycogen was also higher but that of trehalose was lower by $40 \%$ than at the beginning of the experiment. The above results suggest that the synthesis of trehalose - a compound of cryoprotectant character - occurred at low temperatures. A similar phenomenon was observed as a reaction to cooling in case of numerous entomopathogenic nematodes (Jagdale \& Grewal, 2003). It is known that trehalose allows mature individuals of Antarctic nematode Panagrolaimus davidi survive long periods of cold (Wharton et al., 2000). Also the response of Anisakis larvae to freezing at temperatures down $-10^{\circ} \mathrm{C}$ is production of trehalose (Wharton \& Aalders, 2002). It was observed that eggs of Nematodirus battus, as well as A. suum, subjected to an extended cold stress accumulated trehalose and glycogen at the expense of the fat reserves (Lee \& Atkinson, 1976; Ash \& Atkinson, 1983). In our culture maintained at $4^{\circ} \mathrm{C}$ the situation was similar. The levels of both sugars were higher in $A$. simplex larvae (Fig. 1). Nevertheless, further focused studies confirming the suggestion that they are generated from catabolism of lipids are necessary, as that is probable. There is no sure evidence that synthesis of trehalose in nematodes occurs at the cost of glycogen. The observations made during dehydration of Aphelenchus avenae indicate such a possibility. A decrease in glycogen level during that process was accompanied by an increase in trehalose concentration (Madin et al., 1978). Our observation could support the thesis that a reverse process was also possible synthesis of glycogen at the cost of trehalose. During the following days of culturing (from day two through day six) the quantity of trehalose in starved $A$. simplex larvae was reduced at both temperatures and at the low temperature $\left(4^{\circ} \mathrm{C}\right)$ that reduction was significant. During the same time the content of glycogen increased (Fig. 1). Different results were obtained by Castro and Fairbairn (1969) on perforated cuticular-muscular preparations of $A$. suum. In their experiment trehalose was not a substrate for synthesis of glycogen. The divergence in results may result from the difference in the experimental material. Castro and Fairbairn (1969) carried the experiments on isolated body wall segments of mature female of a different species while we worked on live, intact larvae of $A$. simplex.

Concluding on the basis of the results obtained, it can be stated that during $\mathrm{L}_{3}$ larval stage of $A$. simplex the quantity of carbohydrates increased significantly. That might result from adaptation to the living environment, which for $\mathrm{L}_{3}$ larvae is relatively aerobic and relatively anaerobic for $\mathrm{L}_{4}$ larvae. In that last environment the importance of metabolism of carbohydrates is larger (Von Brand, 1979). The data obtained during starving the $\mathrm{L}_{3}$ larvae of $A$. simplex may be the role of trehalose, which is a protective compound at low temperatures while in higher temperatures is a source of energy used first and it also might contribute to restore the level of glycogen. 


\section{Acknowledgements}

The author would like to thank Dr. A. Piotrowicz-Cieślak from the Department of Plant Physiology and Biotechnology, University of Warmia and Mazury, for GLC analyses of sugars.

\section{References}

Adams, A. M., Murrell, K. D., Cross, J. H. (1997): Parasite of fish and risks to public health. Rev. Sci. Tech. Off. Int. Epiz., 16: 652 - 660

Ash, C. P. J., AtKinson, H. J. (1983): Evidence for a temperature-dependent conversion of lipid reserves to carbohydrate in quiescent eggs of the nematode Nematodirus battus. Comp. Biochem. Physiol., 76B: 603-610

BEHM, C. A. (1997): The role of trehalose in the physiology of Nematodes. Int. J. Parasitol., 27: 215 - 229

Castro, G. A., Fairbairn, D. (1969): Comparison of cuticular and intestinal absorption of glucose by adult Ascaris lumbricoides. J. Parasitol., 55: 13 - 16

GRABDA, J. (1976): Studies on the life cycle and morphogenesis of Anisakis simplex (Rudolphi, 1809) (Nematoda: Anisakidae) cultured in vitro. Acta Ichtyol. Piscat., 6: 119 $-140$

Iglesias, L., Valero, A., Adroher, F. J. (1997): Some factors which influence the in vitro maintenance of Anisakis simplex (Nematoda). Folia Parasitol., 44: 297 - 301

JagDAle, G. B., GREWAL, P. S. (2003): Acclimation of entomopathogenic nematodes to novel temperatures: trehalose accumulation and the acquisition of thermotolerance. Int. J. Parasitol., 33: 145 - 152

Kienle, I., Burgert, M., Holzer, H. (1993): Assay of trehalose with acid trehalase purified from Saccharomycetes cerevisiae. Yeast, 9: $607-611$

LeE, D. L., AtKinson, H. J. (1976): Physiology of Nematodes. $2^{\text {nd }}$ edn. The Macmillan Press LTD, London LISOWSKA, S. (1970): Metody kalorymetrycznych oznaczeń cukrów. In ŚLOPEK, S. (Ed): Immunologia praktyczna. PZWL, Warszawa, pp. $649-650$

ŁoPIEŃSKA, E., ŻóŁTOWSKA, K., RoKICKI, J. (2001): The comparison of properties of alfa-amylase from the third and fourth stage of Anisakis simplex larvae. Wiad. Parazytol., 47: 323 - 327

Madin, K. A. C., Crowe, J. H., Loomis, S. H. (1978): Metabolic transition in a nematode during induction and recovery from anhydrobiosis. In CROWE, J. H. and CLEGG, J. S. (Eds): Dry Biological Systems Academy Press, New York, pp. $155-174$

Narain, A. S., Narain, B., Gupta, M. M. (1995): Biochemical studies the intestinal nematode parasite, Asca- ridia galli, of the fowl, Gallus domesticus, cultivated in vitro. J. Liv. World, 2: $81-85$

Smith, J. W., Wootten, R. (1978): Anisakis and anisakiasis. Adv. Parasitology, 16: $93-163$

SÖlLING, H., ESMANN, V. (1975): A sensitive method of glycogen determination in the presence of interfering substances utilizing the filter-paper technique. Anal. Biochem., 68: $664-668$

Strømnes, E., Andersen, K. (2003): Growth of whaleworm (Anisakis simplex, Nematodes, Ascaridoidea, Anisakidae) third-stage larvae in paratenic fish hosts. Parasitol. Res., 89: 335 - 341

Von BRAND, T. (1979): Biochemistry and Physiology of Endoparasites. Elsevier, North Holland Biomedical Press, Amsterdam

WharTON, D. A. (1994): Cold tolerance strategies in nematodes. Biol. Rev., 70, $161-185$

Wharton, D. A., AAlders, O. (2002): The response of Anisakis larvae to freezing. J. Helminthol., 76: $363-368$

Wharton, D. A., Judge, K. F., Worland, M. R. (2000): Cold acclimation and cryoprotectants in freeze-tolerant Antarctic nematode, Panagrolaimus davidi. J. Comp. Physiol. B, 170: $321-327$

Williams, H. H., JONES, A. (1976): Marine helminths and human health. Commonwealth Institute of Helminthology, Miscellaneous publication, 3: $10-36$

Womersley, C. Z., HigA, L. M. (1998): Trehalose: its role in the anhydrobiotic survival of Ditylenchus myceliophagus. Nematologica, 44: 269 - 291

Womersley, C. Z., Smith, L. (1981): Anhydrobiosis in nematodes. I. The role of glycerol, myoinositol and trehalose during dessication. Comp. Biochem. Physiol., 70B: $579-586$

Womersley, C. Z., Thompson, S. N., Smith, L. (1982): Anhydrobiosis in nematodes. II. Carbohydrate and lipid analysis in undesiccated and desiccate nematodes. $J$. Nematol., 14: 145 - 153

ŻóŁTOWSKA, K., ŁoPIEŃSKA, E., LESZCZYŃSKA, K., DMITRY-JUK, M. (1998): The survival Ascaris suum in medium with different concentrations of sugars. Wiad. Parazytol., 44: 496

ŻÓŁTOWSKA, K., ŁOPIEŃSKA, E., ROKICKI, J., DMITRYJUK, M. (2001): The enzymes of carbohydrates metabolism from Cystidicola farionis (Cystidicolidae). Wiad. Parazytol., 47: $311-315$

ŻÓŁTOWSKA, K. , ŁOPIEŃSKA, E., ROKICKI, J., DMITRYJUK, M. (2002): The enzymes of glycogen and trehalose catabolism from Hysterothylacium aduncum (Nematoda: Anisakidae). Folia Parasitol., 49: 239 - 242 